\title{
MAТЕМАТИКА
}

\section{Continuous operator method application for direct and inverse scattering problems}

\author{
I. V. Boykov ${ }^{1}$, V. A. Roudnev ${ }^{2}$, A. I. Boykova ${ }^{1}$, N. S. Stepanov ${ }^{1}$ \\ 1 Penza State University (Penza, Russian Federation), \\ 2 Saint Petersburg State University (St. Petersburg, Russian Federation)
}

\begin{abstract}
We describe the continuous operator method for solution nonlinear operator equations and discuss its application for investigating direct and inverse scattering problems. The continuous operator method is based on the Lyapunov theory stability of solutions of ordinary differential equations systems. It is applicable to operator equations in Banach spaces, including in cases when the Frechet (Gateaux) derivative of a nonlinear operator is irreversible in a neighborhood of the initial value. In this paper, it is applied to the solution of the Dirichlet and Neumann problems for the Helmholtz equation and to determine the wave number in the inverse problem. The internal and external problems of Dirichlet and Neumann are considered. The Helmholtz equation is considered in domains with smooth and piecewise smooth boundaries. In the case when the Helmholtz equation is considered in domains with smooth boundaries, the existence and uniqueness of the solution follows from the classical potential theory. When solving the Helmholtz equation in domains with piecewise smooth boundaries, the Wiener regularization is carried out. The Dirichlet and Neumann problems for the Helmholtz equation are transformed by methods of potential theory into singular integral equations of the second kind and hypersingular integral equations of the first kind. For an approximate solution of singular and hypersingular integral equations, computational schemes of collocation and mechanical quadrature methods are constructed and substantiated. The features of the continuous method are illustrated with solving boundary problems for the Helmholtz equation. Approximate methods for reconstructing the wave number in the Helmholtz equation are considered. Key words: Helmholtz equation, Dirichlet and Neumann boundary values, inverse problems, continuous method for solving operator equations

For citation: I. V. Boykov, V.A. Roudnev, A.I. Boykova, N. S. Stepanov. Continuous operator method application for direct and inverse scattering problems. Zhurnal Srednevolzhskogo matematicheskogo obshchestva. 23:3(2021), 247-272. DOI: https://doi.org/10.15507/20796900.23.202103.247-272
\end{abstract}

\section{Introduction}

The continuous operator method for solving nonlinear operator equations was proposed in [1]. It proved to be useful not only as a numerical technique of solving nonlinear problems which does not require any derivative calculations, but also as a tool of theoretical investigation which made possible to prove some existence theorems for the solutions of such problems [2].

Even though the full strength of the continuous operator method emerges in nonlinear problems, some linear problems - such as wave scattering - provide an instructing illustration of the method and its possible applications. In this paper we apply the method to boundary 
problems for the Helmholtz equation on the base of integral equations of the first and second kind. Besides, we apply the method to inverse problem for Helmgoltz equation.

In [3] it is noted that equations of the first kind are practically not used to solve the Helmholtz equation.

Traditionally, diffraction problems are modeled by Fredholm boundary integral equations of the second kind. As noted in [4], this approach does not allow simulating wave diffraction on thin screens, since this requires the fulfillment of the boundary condition on both sides of the surface.

Recently, hypersingular integral equations of the first kind $[5 ; 4 ; 6 ; 7]$ have been involved in solving scattering problems. In the papers $[6 ; 7]$, when solving the Helmholtz equation, the singularities of the hypersingular integral are regularized and the collocation method is applied to equations with weakly singular and smooth kernels.

In the work [4], when constructing a computational scheme, a feature of the kernel of the hypersingular operator is used. In this case, authors write down the corresponding hypersingular integral equation in the form

$$
\begin{gathered}
\frac{1}{4 \pi} \int_{\sigma} x(\tau) \frac{\partial}{\partial n_{t}} \frac{\partial}{\partial n_{\tau}} \frac{1}{|t-\tau|} d \tau+ \\
+\frac{1}{4 \pi} \int_{\sigma} x(\tau)\left[\frac{\partial}{\partial n_{t}} \frac{\partial}{\partial n_{\tau}}\left[\frac{e^{i k|t-\tau|}}{|t-\tau|}-\frac{1}{|t-\tau|}\right]\right] d \tau=f(t), t \in \sigma,
\end{gathered}
$$

where $x(t)$ is the required function; $f(t)$ is the given function; $n_{t}$ and $n_{\tau}$ are unit normals.

In this paper, to solve the Helmholtz equation with the Dirichlet and Neumann boundary conditions, integral equations of both the first and second kind are used. A comparison (in terms of accuracy) of the results obtained is carried out. A numerical experiment is carried out for solving the Helmholtz equation in a domain with a piecewise-smooth boundary using Wiener regularization. A comparison is made of the results of solving the Helmholtz equation in a domain with a piecewise smooth boundary with and without Wiener regularization.

The aim of the work is: construction, on the basis of a continuous method for solving operator equations, numerical methods for solving the Helmholtz equation, represented by integral equations of the first and second kind, comparison in accuracy of solutions of boundary value problems for the Helmholtz equation modeled by integral equations of the first and second kind, construction of a new method of justification approximate methods for solving hypersingular integral equations. Besides we solve the problem of restoration the wave number of Helmgoltz equation.

We shall see that for more singular problems the continuous operator method not only converges to the solution, but can also outperform direct solvers.

\section{Continuous operator method}

Consider an equation

$$
A(x)-f=0,
$$

where $A(x)$ is a nonlinear operator mapping from Banach space $X$ to $X$.

Let $x^{*}$ be a solution of the equation (2.1). In [1] the connection between stability of solutions of operator differential equations in Banach spaces and resolving operator equations of the form (2.1) has been established. Here we shall summarize the results on the method. 
Let $B$ be a Banach space, $a, z \in B, K$ be a linear operator mapping from $B$ to $B, \Lambda(K)$ be the logarithmic norm [8] of the operator $K$, and $I$ be the identity operator. We shall use the following notation:

$$
\begin{gathered}
B(a, r)=\{z \in B:\|z-a\| \leq r\}, \\
S(a, r)=\{z \in B:\|z-a\|=r\}, \\
\mathcal{R} e K=K_{R}=\left(K+K^{*}\right) / 2, \\
\Lambda(K)=\lim _{h \downarrow 0}(\|I+h K\|-1) / h .
\end{gathered}
$$

Logarithmic norm examples. Let a complex matrix $A=\left\{a_{i j}\right\}, i, j=1,2, \ldots, n$, be given in $n$-dimensional space $\mathbb{R}^{n}$ of vectors $x$ with the norms

$$
\begin{gathered}
\|x\|_{1}=\sum_{k=1}^{n}\left|x_{k}\right|, \\
\|x\|_{2}=\left[\sum_{k=1}^{n}\left|x_{k}\right|^{2}\right]^{1 / 2},
\end{gathered}
$$

and

$$
\|x\|_{3}=\max _{1 \leq k \leq n}\left|x_{k}\right| .
$$

The corresponding logarithmic norms of the matrix $A$ then read [9]:

$$
\begin{gathered}
\Lambda_{1}(A)=\max _{j}\left(\mathcal{R} e\left(a_{j j}\right)+\sum_{i=1, i \neq j}^{n}\left|a_{i j}\right|\right), \\
\Lambda_{2}(A)=\lambda_{\max }\left(\frac{A+A^{T}}{2}\right), \\
\Lambda_{3}(A)=\max _{i}\left(\mathcal{R} e\left(a_{i i}\right)+\sum_{j=1, j \neq i}^{n}\left|a_{i j}\right|\right) .
\end{gathered}
$$

Here $\lambda_{\max }(Z)$ stands for the real part of the largest real part eigenvalue of the matrix $Z$.

Let us associate the equation (2.1) with the following Cauchy problem

$$
\begin{gathered}
\frac{d x(t)}{d t}=A(x(t))-f, \\
x(0)=x_{0} .
\end{gathered}
$$

T h e o r e m 2.1 (Boikov, [1]) Let the equation (2.1) have a solution $x^{*}$ and on any differentiable curve $g(t)$ in Banach space $B$ the inequality is valid

$$
\lim _{t \rightarrow \infty} \frac{1}{t} \int_{0}^{t} \Lambda\left(A^{\prime}(g(\tau)) d \tau \leq-\alpha_{g}, \alpha_{g}>0 .\right.
$$

Then the solution of the Cauchy problem (2.2)-(2.3) converges to the solution $x^{*}$ of the equation (2.1) for any initial approximation. 
T h e o r e m 2.2 (Boikov, [1]) Let the equation (2.1) has a solution $x^{*}$ and for any differentiable curve $g(t)$ in a ball $B\left(x^{*}, r\right)$ the following conditions are satisfied:

1) for any $t(t>0)$

$$
\int_{0}^{t} \Lambda\left(A^{\prime}(g(\tau)) d \tau \leq 0\right.
$$

2) the inequality (2.4) is valid.

Then the solution of the Cauchy problem (2.2)-(2.3) converges to a solution of the equation (2.1).

$\mathbf{N}$ o t a t i o $\mathbf{n} \mathbf{2 . 1}$ In the inequality (2.4) it is assumed that the constants $\alpha_{g}>0$ can differ for different curves $g(t)$.

N o t a t i o n 2.2 From inequalities (2.4)-(2.5) it follows that the logarithmic norm $\Lambda\left(A^{\prime}(g(\tau))\right.$ can be positive for some values of $\tau$; i.e. the Frechet derivative $A^{\prime}(g(\tau))$ can degenerate into an identically zero operator along the curve.

N o t a t i o n 2.3 An example in [2] (an approximate solution of a hypersingular integral equation) has demonstrated convergence of an iterative process based on a continuous operator method when the Frechet derivative vanishes at the initial approximation.

$\mathbf{N}$ o t a t i o $\mathbf{n} 2.4$ Logarithmic norm has the property which is very useful for numerical analysis.

Let $A, B$ be square matrices of order $n$ with complex elements and $x=\left(x_{1}, \ldots, x_{n}\right)$, $y=\left(y_{1}, \ldots, y_{n}\right), \xi=\left(\xi_{1}, \ldots, \xi_{n}\right), \eta=\left(\eta_{1}, \ldots, \eta_{n}\right)$ are $n$-dimensional vectors with complex components. Let us consider the following systems of algebraic equations: $A x=\xi$ and $B y=\eta$. The norm of a vector and its subordinate operator norm of the matrix are fixed; the logarithmic norm $\Lambda(A)$ corresponds to the operator norm.

T h e o r e m 2.3 (Lozinskii, [10]) If $\Lambda(A)<0$, the matrix $A$ is non-singular and $\left\|A^{-1}\right\| \leq 1 /|\Lambda(A)|$.

T h e o r e m 2.4 (Lozinskii, [10]) Let $A x=\xi, B y=\eta$ and $\Lambda(A)<0, \Lambda(B)<0$. Then

$$
\|x-y\| \leq \frac{\|\xi-\eta\|}{|\Lambda(B)|}+\frac{\|A-B\|}{|\Lambda(A) \Lambda(B)|} .
$$

Main properties of the logarithmic norm are given in [8].

$\mathbf{N}$ o t a t i o n 2.5 The logarithmic norm of the operator $K$ can have different (positive or negative) values in different spaces.

Described above continuous method for solving nonlinear operator equations admits the following generalization.

Let us return to the equation (2.1). Denote by $A^{\prime}\left(x_{0}\right) x$ the Gateaux (Frechet) derivative on a element $x_{0}$. We introduce the equation

$$
\left(A^{\prime}\left(x_{0}\right)\right)^{*} A(x)-\left(A^{\prime}\left(x_{0}\right)\right)^{*} f=0 .
$$

Equation (2.6) is associated with the Cauchy problem

$$
\frac{d x(t)}{d t}=-\left(\left(A^{\prime}\left(x_{0}\right)\right)^{*} A(x)-\left(A^{\prime}\left(x_{0}\right)\right)^{*} f\right),
$$




$$
x(0)=x_{0} .
$$

If $\left.\Lambda_{2}\left(A^{\prime}\left(x_{0}\right)\right)^{*} A^{\prime}\left(x_{0}\right)\right)>0$, then in some neighborhood $B\left(x_{0}, r\right)$ of the element $x_{0}$ logarithmic norm $\left.\Lambda_{2}\left(A^{\prime}\left(x_{0}\right)\right)^{*} A^{\prime}(x)\right)$ will be positive. Therefore, there is a time interval $\left[t_{0}, t_{1}\right]$ in which $\left\|x\left(t_{1}\right)\right\|<\|x(0)\|$ for $t_{0}<t \leq t_{1}$. Here $x(t)$ is the solution to the Cauchy problem (2.7)-(2.8).

For $t \geq t_{1}$, consider the Cauchy task

$$
\begin{gathered}
\frac{d \tilde{x}(t)}{d t}=-\left(\left(A^{\prime}\left(x_{1}\right)\right)^{*} A(\tilde{x}(t))-\left(A^{\prime}\left(x_{1}\right)\right)^{*} f\right), x_{1}=x\left(t_{1}\right), \\
\tilde{x}\left(t_{1}\right)=x\left(t_{1}\right)
\end{gathered}
$$

and define the segment $\left[t_{1}, t_{2}\right]$, in which $\Lambda_{2}\left(\left(A^{\prime}\left(\tilde{x}\left(t_{1}\right)\right)\right)^{*} A^{\prime}(\tilde{x}(t))\right)>0$ and $\left\|x\left(t_{2}\right)\right\|<\left\|x\left(t_{1}\right)\right\|$.

Continuing this process, we have $\lim _{t \rightarrow \infty} \frac{\|d x(t)\|}{d t}=0$ and therefore $\lim _{t \rightarrow \infty} x(t)=x^{*}$.

T h e o $\mathbf{r}$ e m 2.5 Let equation (2.6) have a solution $x^{*}$ and for any differentiable curve in $B$ the inequality

$$
\int_{0}^{t} \Lambda_{2}\left(\left(A^{\prime}(g(\tau))\right)^{*} A^{\prime}(g(\tau))\right) d \tau>0 .
$$

Then the solution of the Cauchy problems ((2.7)-(2.8)), ((2.9)-(2.10)), etc. converges to the solution $x^{*}$ of the equation (2.6).

If the conditions of Theorem 2.5 are not satisfied, the regularization is carried out

$$
\frac{d x(t)}{d t}=-\alpha x(t)-\left(\left(A^{\prime}\left(x\left(t_{k}\right)\right)\right)^{*} A(x)-\left(A^{\prime}\left(x\left(t_{k}\right)\right)\right)^{*} f\right)
$$

on segments $\left[t_{k}, t_{k+1}\right], k=0,1, \ldots$, in which $\Lambda_{2}\left(\left(A^{\prime}\left(x\left(t_{k}\right)\right)\right)^{*} A^{\prime}(x(t))\right)>0, t \in\left[t_{k}, t_{k+1}\right]$. Here $\alpha$ is a parameter of regularization.

\section{Integral equations of the first kind}

Consider the Helmholtz equation

$$
\Delta u+k^{2} u=0
$$

where $k=\|\mathbf{k}\|>0$ is the wave number corresponding to some wave vector $\mathbf{k}$.

We look for the solutions that can be presented as a superposition of an incident plane wave and a scattered wave

$$
u=u_{0}(x ; \mathbf{k})+\tilde{u} .
$$

$u_{0}$ is a plane wave, $\tilde{u}$ is a the scattered spherical wave satisfying the radiation condition.

The interaction of an incident wave with a scatterer can be modelled with homogeneous boundary conditions that lead to standard boundary problems for a domain $D$ with a boundary $\partial D \in C_{2}$.

Dirichlet interior problem. Find $u \in C^{2}(D) \cap C(\bar{D})$ satisfying the Helmholtz's equation in $D$ and the boundary condition

$$
u=\left.f\right|_{\partial D},
$$

where $f$ is a given continuous function. 
Dirichlet exterior problem. Find $u \in C^{2}\left(\mathbb{R}^{3} \backslash \bar{D}\right) \cap C\left(\mathbb{R}^{3} \backslash D\right)$ satisfying the Helmholtz's equation in $\mathbb{R}^{3} \backslash D$, Sommerfeld's radiation condition at infinity, and the boundary condition

$$
u=\left.f\right|_{\partial D},
$$

where $f$ is a given continuous function.

Neumann interior problem. Find $u \in C^{2}(D) \cap C(\bar{D})$ having the normal derivative everywhere on $\partial D$, satisfying the Helmholtz's equation in $D$, and the boundary condition

$$
\frac{d u}{d n}=\left.f\right|_{\partial D}
$$

where $f$ is a given continuous function, $n$ is the unit normal vector.

Neumann exterior problem. Find $u \in C^{2}\left(\mathbb{R}^{3} \backslash \bar{D}\right)$ satisfying the Helmholtz's equation, Sommerfeld's radiation condition, and the boundary condition

$$
\frac{d u}{d n}=\left.f\right|_{\partial D}
$$

where $f$ is a given continuous function, $n$ is the unit normal vector.

Let $\Phi(x, y)$ be the fundamental solution of the Helmholtz's equation in $\mathbb{R}^{3}$ :

$$
\Phi(x, y ; k)=\frac{1}{4 \pi} \frac{e^{i k|x-y|}}{|x-y|},
$$

$x, y \in \mathbb{R}^{3}$, or for $x, y \in \mathbb{R}^{2}$

$$
\Phi(x, y ; k)=\frac{i}{4} H_{0}^{(1)}(k|x-y|)
$$

where $H_{0}^{(1)}(z)$ stands for the Hankel function of the first kind. The following statements hold [3].

T h e o r e m 3.1 (see D. Colton and R. Kress, [3]) A simple-layer potential

$$
u(x)=\int_{\partial D} \Phi(x, y ; k) \varphi(y) d s(y), x \in \mathbb{R}^{3} \backslash \partial D,
$$

with continuous density $\varphi$ solves the Dirichlet problems (3.2) and (3.3), if $\varphi$ is a solution of the integral equation

$$
\int_{\partial D} \Phi(x, y ; k) \varphi(y) d s(y)=f(x), x \in \partial D .
$$

T h e o r e m 3.2 (see D. Colton and R. Kress, [3]) A double-layer potential

$$
u(x)=\int_{\partial D} \frac{\partial \Phi(x, y ; k)}{\partial n(y)} \varphi(y) d s(y), x \in \mathbb{R}^{3} \backslash \partial D
$$

with density $\varphi$ solves the Neumann problems (3.4) and (3.5), if $\varphi$ is a solution of the singular integral equation

$$
\frac{\partial}{\partial n(x)} \int_{\partial D} \frac{\partial \Phi(x, y ; k)}{\partial n(y)} \varphi(y) d s(y)=f(x), x \in \partial D .
$$


$\mathbf{N}$ o t a t i o $\mathbf{n} 3.1$ Theorems 3.1 and 3.2 are valid under the assumption that the boundary $\partial D$ belongs to the space $C^{2}$. If this condition is violated, it is necessary to construct a generalized solution. One of the ways to construct generalized solutions is Wiener regularization. It is as follows. Let us describe the Wiener regularization of interior problems with Dirichlet and Neumann boundary conditions. Since the construction of the regularization is carried out in the same way for the Dirichlet and Neumann boundary conditions, we will dwell on the consideration of the Helmholtz equation with Dirichlet boundary condition. Let $\left\{D_{m}\right\}$ be a sequence of domains with infinitely smooth boundaries that approximates the domain $D$, and $D_{m} \subset D_{m+1} \subset \cdots \subset D$. This inclusion implies that any point $P \in D$ for sufficiently large $m$ belongs to $D_{m}$. Let $F(x)$ be a continuous function in $\bar{D}$ that coincides with $f(x)$ on the boundary $\partial D$. Let us denote by $u_{m}(x)$ the solution of the Dirichlet problem for the Helmholtz equation under the boundary condition $\left.u_{m}(x)\right|_{\partial D_{m}}=F(x)$. It follows from Theorem 3.1 that such a solution exists. The Wiener generalized solution to problem (3.2) is the limit $u_{f}(x)=\lim _{m \rightarrow \infty} u_{m}(x), x \in D$ if such a limit exists and does not depend on the choice of the sequences $D_{m}$ and the way to build them.

A large number of works have been devoted to the construction of generalized solutions of equations of mathematical physics, of which we will present review works: [11-12].

\section{Numerical approach and illustrations}

Let us apply the method to the Dirichlet problem for the Helmholtz equation in $\mathbb{R}^{2}$.

$$
\frac{i}{4} \int_{\partial D} H_{0}^{(1)}(k|x-y|) \varphi(y) d s(y)=f(x), x \in \partial D,
$$

where $D$ is a closed bounded domain.

Consider a set of points $x_{l}, l=1, \ldots, n$ distributed over the surface $\partial D$. An approximate solution of the equation (4.1) is sought as

$$
\varphi_{n}(y)=\sum_{k=1}^{n} \alpha_{k} \psi_{k}(y)
$$

where $\psi_{k}(y)$ are basic functions defined on $\partial D$ and, possibly, localized in the vicinity of the points $x_{l}, l=1, \ldots, n$.

We associate the following system of approximate collocation equations with the equation (4.1):

$$
\begin{gathered}
\sum_{j=1}^{n} \alpha_{j} \frac{i}{4} \int_{\partial D} H_{0}^{(1)}\left(k\left|x_{l}-y\right|\right) \psi_{j}(y) d s(y)=f\left(x_{l}\right), \\
l=1, \ldots, n .
\end{gathered}
$$

Here $x_{l}, l=1, \ldots, n$ are the collocation points.

Replace integrals in the left-hand side of eq. (4.2) with a quadrature formula. Finally, it yields the system of equations

$$
\sum_{j=1}^{n} R_{l j} \alpha_{j}=f\left(x_{l}\right), l=1, \ldots, n
$$


where $R_{l j}=\frac{i}{4} \sum_{v=0}^{n_{q}} p_{v} H_{0}^{(1)}\left(k\left|x_{l}-y_{v}\right|\right) \psi_{j}\left(y_{v}\right)$. Here $p_{v}, v=0, \ldots, n_{q}$ and $y_{v}, v=0, \ldots, n_{q}$ are the weights and nodes of the quadrature formula.

According to the continuous operator method, we associate the equation (4.3) with the following system of differential equations

$$
\frac{d \alpha_{l}(t)}{d t}=\beta_{l}\left[\sum_{j=1}^{n} R_{l j} \alpha_{j}-f\left(x_{l}\right)\right], l=1, \ldots, n .
$$

The values of

$$
\beta_{l}=-e^{i \arg \left(R_{l l}\right)}, l=1, \ldots, n
$$

are chosen so that the logarithmic norms $\Lambda_{1}$ or $\Lambda_{3}$ are minimized.

Negative logarithmic norm of the matrix in the right hand side of (4.4) guarantees that the solution of the differential equations system converges to the solution of the system (4.3) as $t \rightarrow \infty$.

The system (4.4) can be solved by any numerical method. Model examples are solved by Euler or Runge-Kutta methods.

Computational schemes for solving the Helmholtz equation with other boundary conditions are constructed similarly.

Let us stay in more detail on the construction of a spline-collocation computational scheme with zero-order splines for solving the 3D Dirichlet problem for the Helmholtz equation

$$
\frac{1}{4 \pi} \int_{\partial D} \frac{e^{i k|x-y|}}{|x-y|} \varphi(y) d s(y)=f(x), \quad x \in \partial D .
$$

Without loss of generality, we will assume that $D$ is a star-shaped surface centered at a point $x^{*} \in D$.

Let's triangulate the surface $\partial D$ with triangles «close» to equilateral. When constructing a triangulation, we require that the vertices of the triangles lie on the surface $\partial D$. Let us denote these nodes as $x_{k}, k=1,2, \ldots, N_{0}$. Triangulation algorithms are described in sufficient detail in the works [13], [14].

As a result, the surface $\partial D$ is approximated by the surface $\partial D_{N}$, and the equation (4.6) is approximated by the equation

$$
\frac{1}{4 \pi} \int_{\partial D_{N}} \frac{e^{i k|x-y|}}{|x-y|} \varphi(y) d s(y)=f(x), \quad x \in \partial D .
$$

An approximate solution to the equation (4.7) will be sought in the form of a function

$$
\varphi_{N}(y)=\sum_{k=1}^{N} \alpha_{k} \psi_{k}(y)
$$

where

$$
\psi_{k}(y)=\left\{\begin{array}{l}
1, \quad y \in \Delta_{k} \\
0, \quad y \in \partial D_{N} \backslash \Delta_{k}
\end{array}\right.
$$

$k=1,2 \ldots, N ; \Delta_{k}$ is a element of the surface $\partial D_{N}$.

Denote by $\bar{x}_{k}$ a point belonging to $\Delta_{k}$. As such a point, you can take the center of a circle inscribed in a triangle $\Delta_{k}$. 
The coefficients $\alpha_{k}$ of the function (4.8) are determined from the system of linear algebraic equations

$$
\frac{1}{4 \pi} \sum_{l=1}^{N} \int_{\Delta_{l}} \alpha_{l} \frac{e^{i k\left|\bar{x}_{j}-y\right|}}{\left|\bar{x}_{j}-y\right|} d s(y)=f\left(\bar{x}_{j}^{*}\right)
$$

$j=1, \ldots, N$.

Here the point $\bar{x}_{j}^{*}$ is intersection of the straight line passing through the points $x^{*}$ and $x_{j}$ with the surface $\Delta_{j}$.

A simpler, but less accurate computational scheme has the form

$$
\frac{1}{4 \pi} \sum_{l=1}^{N}{ }^{\prime} \alpha_{l} \frac{e^{i k\left|\bar{x}_{j}-y_{l}\right|}}{\left|\bar{x}_{j}-y_{l}\right|} \operatorname{mes}\left(\Delta_{l}\right)+\frac{1}{4 \pi} \int_{\Delta_{j}} \alpha_{j} \frac{e^{i k\left|\bar{x}_{j}-y\right|}}{\left|\bar{x}_{j}-y\right|} d s(y)=f\left(\bar{x}_{j}^{*}\right),
$$

$j=1, \ldots, N$.

Here mes $\left(\Delta_{l}\right)$ denote the square of the triangle $\Delta_{l}$ and by $\sum_{l=1}^{N}$ ' is indicated that $l \neq j$.

We will demonstrate the method of substantiating the spline collocation method using the computational scheme (4.9).

$\mathbf{T} \mathbf{h}$ e o $\mathbf{r} \mathbf{e} \mathbf{m} \mathbf{4 . 1}$ Let the following conditions be satisfied:

1) The equation (4.6) has a solution $\varphi^{*}(x)$ for the given right-hand side;

2) The logarithmic norm of the matrix $A_{N}$ on the left-hand side of the system of equations (4.9) is negative in the metric of some Banach space $B$ and $\Lambda\left(A_{N}\right) \leq-\gamma_{0}$ for all $N \geq N_{0}$;

3) $D$ is a star-shaped surface centered at a point $x^{*} \in D$;

4) The solution $\varphi^{*}(y)$ of the equation (4.6) belongs to the class of functions $W^{2}(M)$ having continuous derivatives of the first order and piecewise continuous derivatives of the second order bounded in modulus by the constant $M$;

5) The surface $\partial D$ is a Lyapunov surface.

Then the system of equations (4.9) has a unique solution $\varphi_{N}^{*}(y)$ converging to $\varphi^{*}(y)$ for $N \rightarrow \infty$.

$\mathbf{R} \mathbf{e} \mathbf{m}$ a $\mathbf{r} \mathbf{k} 4.1$ Note that, in contrast to the many well-known methods of substantiating approximate methods for solving integral equations, here only the solvability of the considered equation with the given right hand part is required.

P r o o f.

Since the logarithmic norm $\Lambda\left(A_{N}\right)$ of the matrix $A_{N}$ is negative for $N \geq N_{0}$, the Theorem 2.3 implies the unique solvability of the system of equations (4.9).

Let us denote by $\varphi^{*}(x)$ a solution of the equation (4.6). Then

$$
\frac{1}{4 \pi} \int_{\partial D} \frac{e^{i k|x-y|}}{|x-y|} \varphi^{*}(y) d s(y)=f(x), \quad x \in \partial D .
$$

Draw planes from the point $x^{*}$ through the vertices $x_{k}$ of the triangles $\Delta_{k}$ to the intersection with the surface $\partial D$. The surfaces that cut out the constructed planes from $\partial D$ are denoted by $\partial \tilde{D}_{k}, k=1,2, \ldots, N$.

Then the equation (4.11) can be represented as

$$
\frac{1}{4 \pi} \sum_{l=1}^{N} \int_{\partial \tilde{D}_{l}} \frac{e^{i k|x-y|}}{|x-y|} \varphi^{*}(y) d s(y)=f(x), \quad x \in \partial D .
$$


At the points $\bar{x}_{j}^{*}, j=1,2, \ldots, N$ we have

$$
\frac{1}{4 \pi} \sum_{l=1}^{N} \int_{\partial \tilde{D}_{l}} \frac{e^{i k\left|\bar{x}_{j}^{*}-y\right|}}{\left|\bar{x}_{j}^{*}-y\right|} \varphi^{*}(y) d s(y)=f\left(\bar{x}_{j}^{*}\right), \quad j=1,2, \ldots, N .
$$

The difference between the equations (4.9) and (4.13) can be represented as follows

$$
\begin{aligned}
& \frac{1}{4 \pi} \sum_{l=1}^{N} \int_{\Delta_{l}} \frac{e^{i k\left|\bar{x}_{j}-y\right|}}{\left|\bar{x}_{j}-y\right|}\left(\varphi_{N}(y)-\tilde{\varphi}_{l}^{*}(y)\right) d s(y)= \\
& =\frac{1}{4 \pi} \sum_{l=1}^{N}\left[\int_{\Delta_{l}} \frac{e^{i k\left|\bar{x}_{j}-y\right|}}{\left|\bar{x}_{j}-y\right|} \tilde{\varphi}_{l}^{*}(y) d s(y)-\right. \\
& \left.-\int_{\partial \tilde{D}_{l}} \frac{e^{i k\left|\bar{x}_{j}^{*}-y\right|}}{\left|\bar{x}_{j}^{*}-y\right|} \varphi^{*}(y) d s(y)\right], j=1, \ldots, N .
\end{aligned}
$$

Here $\tilde{\varphi}_{l}^{*}(y)$ is the linear function taking values $\varphi^{*}(y)$ at the vertices of the triangle $\Delta_{l}, l=1,2, \ldots, N$.

We introduce the notations

$$
\begin{aligned}
& g_{j}^{N}=\frac{1}{4 \pi} \sum_{l=1}^{N}\left[\int_{\Delta_{l}} \frac{e^{i k\left|\bar{x}_{j}-y\right|}}{\left|\bar{x}_{j}-y\right|} \tilde{\varphi}_{l}^{*}(y) d s(y)-\right. \\
& \left.-\int_{\partial \tilde{D}_{l}} \frac{e^{i k\left|\bar{x}_{j}^{*}-y\right|}}{\left|\bar{x}_{j}^{*}-y\right|} \varphi^{*}(y) d s(y)\right], j=1, \ldots, N .
\end{aligned}
$$

Let's start evaluating the expression $g_{j}^{N}$.

Without loss of generality, we can assume that the function $\varphi^{*}(y)$ has continuous secondorder partial derivatives in the domain $D$, bounded in modulus by the constant $M$.

Starting to estimate $g_{j}^{N}$, we first estimate the term

$$
I_{1}=\frac{1}{4 \pi} \int_{\Delta_{j}} \frac{e^{i k\left|\bar{x}_{j}-y\right|}}{\left|\bar{x}_{j}-y\right|} \tilde{\varphi}^{*}(y) d s(y)-\frac{1}{4 \pi} \int_{\partial \tilde{D}_{j}} \frac{e^{i k\left|\bar{x}_{j}^{*}-y\right|}}{\left|\bar{x}_{j}^{*}-y\right|} \varphi^{*}(y) d s(y) .
$$

Without loss of generality, we can assume that the triangle $\Delta_{j}$ lies on the plane $O X Y$.

Let be $x=\left(x_{1}, x_{2}, x_{3}\right), y=\left(y_{1}, y_{2}, y_{3}\right)$.

We will assume that the surface $\partial \tilde{D}_{j}$ is described by a function $y_{3}=\psi_{j}\left(y_{1}, y_{2}\right),\left(y_{1}, y_{2}\right) \in$ $\in \Delta_{j}, j=1,2, \ldots, N, \psi_{j}\left(y_{1}, y_{2}\right) \in W^{1,1}(M)$. 
Then

$$
\begin{aligned}
& I_{1}=\left|\frac{1}{4 \pi} \int_{\partial \tilde{D}_{j}} \frac{\mid e^{i k\left|\bar{x}_{j}^{*}-y\right|}-e^{i k\left|\bar{x}_{j}-y\right|}}{\left|\bar{x}_{j}^{*}-y\right|} \varphi^{*}(y) d s(y)\right|+ \\
& +\left|\frac{1}{4 \pi} \int_{\partial \tilde{D}_{j}} e^{i k\left|\bar{x}_{j}-y\right|}\left(\frac{1}{\left|\bar{x}_{j}^{*}-y\right|}-\frac{1}{\left|\bar{x}_{j}-y\right|}\right) \varphi^{*}(y) d s(y)\right|+ \\
& +\left|\frac{1}{4 \pi} \int_{\partial \tilde{D}_{j}} \frac{e^{i k\left|\bar{x}_{j}-y\right|}}{\left|\bar{x}_{j}-y\right|} \varphi^{*}(y) d s(y)-\frac{1}{4 \pi} \int_{\Delta_{j}} \frac{e^{i k\left|\bar{x}_{j}-y\right|}}{\left|\bar{x}_{j}-y\right|} \tilde{\varphi}^{*}(y) d s(y)\right|= \\
& =I_{11}+I_{12}+I_{13} .
\end{aligned}
$$

It is not hard to see that

$$
\begin{gathered}
I_{11} \leq \frac{C}{N}\left|\int_{\partial \tilde{D}_{j}} \frac{\varphi^{*}(y) d s(y)}{\left|\bar{x}_{j}^{*}-y\right|}\right| \leq \frac{C}{N^{2}} \\
I_{12} \leq C\left|\int_{\partial \tilde{D}_{j}} \frac{|| \bar{x}_{j}-y|-| \bar{x}_{j}^{*}-y||}{\left|\bar{x}_{j}^{*}-y\right|\left|\bar{x}_{j}-y\right|} d s(y)\right| \leq \\
\leq C\left|\int_{\partial \tilde{D}_{j}} \frac{\sum_{i=1}^{3}\left(\left|\bar{x}_{i}(j)-\bar{x}_{i}^{*}(j)\right||| \bar{x}_{i}^{*}(j)-y_{i}|+| \bar{x}_{i}(j)-y_{i}||\right)^{1 / 2}}{\left|\bar{x}_{j}^{*}-y\right|\left|\bar{x}_{j}-y\right|} d s(y)\right| \leq \\
\leq \frac{C}{N^{1 / 2}}\left|\int_{\partial \tilde{D}_{j}} \frac{d s(y)}{\left|\bar{x}_{j}^{*}-y\right|^{1 / 2}\left|\bar{x}_{j}-y\right|}\right| \leq \frac{C}{N} .
\end{gathered}
$$

Here we have used folowing notations $\bar{x}_{j}=\left(\bar{x}_{1}(j), \bar{x}_{2}(j), \bar{x}_{3}(j)\right)$.

Let us introduce the notation $v=\left(v_{1}, v_{2}, v_{3}\right), v_{1}=y_{1}, v_{2}=y_{2}, v_{3}=\psi\left(y_{1}, y_{2}\right)$.

We transform the integral

$$
\begin{aligned}
& \left|\frac{1}{4 \pi} \int_{\partial \tilde{D}_{j}} \frac{e^{i k\left|\bar{x}_{j}-y\right|}}{\left|\bar{x}_{j}-y\right|} \varphi^{*}(y) d s(y)\right|= \\
& =\left|\frac{1}{4 \pi} \int_{\Delta_{j}} \frac{e^{i k\left|\bar{x}_{j}-v\right|}}{\left|\bar{x}_{j}-v\right|} \varphi^{*}(v)\left(1+\left(\frac{\partial \psi}{\partial y_{1}}\right)^{2}+\left(\frac{\partial \psi}{\partial y_{2}}\right)^{2}\right)^{1 / 2} d s(y)\right| .
\end{aligned}
$$

Then

$$
\begin{aligned}
& I_{13}=\left|\frac{1}{4 \pi} \int_{\Delta_{j}} \frac{e^{i k\left|\bar{x}_{j}-v\right|}-e^{i k\left|\bar{x}_{j}-y\right|}}{\left|\bar{x}_{j}-v\right|} \varphi^{*}(v)\left(1+\left(\frac{\partial \psi}{\partial y_{1}}\right)^{2}+\left(\frac{\partial \psi}{\partial y_{2}}\right)^{2}\right)^{1 / 2} d s(y)\right|+ \\
& +\left|\frac{1}{4 \pi} \int_{\Delta_{j}} e^{i k\left|\bar{x}_{j}-y\right|}\left(\frac{1}{\left|\bar{x}_{j}-v\right|}-\frac{1}{\left|\bar{x}_{j}-y\right|}\right) \varphi^{*}(v)\left(1+\left(\frac{\partial \psi}{\partial y_{1}}\right)^{2}+\left(\frac{\partial \psi}{\partial y_{2}}\right)^{2}\right)^{1 / 2}\right|+ \\
& +\left|\frac{1}{4 \pi} \int_{\Delta_{j}} \frac{e^{i k\left|\bar{x}_{j}-y\right|}}{\left|\bar{x}_{j}-y\right|}\left(\left(1+\left(\frac{\partial \psi}{\partial y_{1}}\right)^{2}+\left(\frac{\partial \psi}{\partial y_{2}}\right)^{2}\right)^{1 / 2}-1\right) \varphi^{*}(v) d s(y)\right|+ \\
& +\left|\frac{1}{4 \pi} \int_{\Delta_{j}} \frac{e^{i k\left|\bar{x}_{j}-y\right|}}{\left|\bar{x}_{j}-y\right|}\left(\varphi^{*}(v)-\tilde{\varphi}^{*}(y)\right) d s(y)\right|= \\
& =I_{131}+\cdots+I_{134} .
\end{aligned}
$$

I. V. Boykov, V. A. Roudnev, A. I. Boykova, N. S. Stepanov. Continuous operator method application for ... 
Let's estimate each term separately:

$$
\begin{gathered}
I_{131} \leq C|| \bar{x}_{j}-v|-| \bar{x}_{j}-y||\left|\int_{\Delta_{j}} \frac{\varphi^{*}(v)\left(1+\left(\frac{\partial \psi}{\partial y_{1}}\right)^{2}+\left(\frac{\partial \psi}{\partial y_{2}}\right)^{2}\right)^{1 / 2}}{\left|\bar{x}_{j}-v\right|} d s(y)\right| \leq \\
\leq \frac{C}{N} \mid \int_{\Delta_{j}} \frac{d s(y)}{\left|\bar{x}_{j}-v\right|} \leq \frac{C}{N^{3 / 2}} ; \\
I_{132} \leq C \mid \int \frac{|| \bar{x}_{j}-v|-| \bar{x}_{j}-y \mid d s(y)}{\left|\bar{x}_{j}-y\right|\left|\bar{x}_{j}-v\right|} \leq \\
\leq C \mid \int_{\Delta_{j}} \frac{\left|\psi\left(y_{1}, y_{2}\right)\right|^{1 / 2}\left(\left|\bar{x}_{3}(j)\right|+\left|\bar{x}_{3}(j)-\psi\left(y_{1}, y_{2}\right)\right|\right)^{1 / 2} d s(y)}{\left|\bar{x}_{j}-y\right|\left|\bar{x}_{j}-v\right|} \leq \\
\leq C \mid \int_{\Delta_{j}} \frac{d s(y)}{\left|\bar{x}_{j}-y\right|} \leq \frac{C}{N^{3 / 2}} ; \quad \leq \frac{C}{N^{3 / 2}} ; \\
I_{133} \leq \frac{d s(y)}{\left|\bar{x}_{j}-y\right|} \leq \frac{C}{\Delta_{j}} . \\
I_{134} \leq \frac{C}{N} \int_{\Delta_{j}} \frac{d s(y)}{\left|\bar{x}_{j}-y\right|} \leq \frac{C}{N^{3 / 2}} .
\end{gathered}
$$

From the inequalities (4.19) - (4.23) we have

$$
I_{13} \leq \frac{C}{N^{3 / 2}}
$$

Collecting estimates (4.17)-(4.18), (4.24), we arrive at the inequality

$$
I_{1} \leq \frac{C}{N}
$$

Let us estimate the summ

$$
\begin{gathered}
I_{2}=\frac{1}{4 \pi} \sum_{l=1, l \neq j}^{N} \mid \int_{\Delta_{l}} \frac{e^{i k\left|x_{j}-y\right|}}{\left|x_{j}-y\right|} \tilde{\varphi}_{l}^{*}(y) d s(y)- \\
-\int_{\partial \tilde{D}_{l}} \frac{e^{i k\left|x_{j}-y\right|}}{\left|x_{j}-y\right|} \varphi^{*}(y) d s(y) \mid, j=1, \ldots, N .
\end{gathered}
$$

Repeating the above reasoning, we arrive at the following estimate $I_{2} \leq C \frac{1}{N^{1 / 2}}$.

From estimates for $I_{1}, I_{2}$ we have $g_{J}^{N} \leq C_{\frac{1}{N^{1} / 2}}$.

It is not hard to see that $\lim _{N \rightarrow \infty} \max _{1 \leq j \leq N}\left|g_{j}^{N}(x)\right|=0$. Hence and from the inequality $\left\|A^{-1}\right\| \leq 1 /\left|\gamma_{0}\right|$ implies the estimate $\lim _{N \rightarrow \infty} \max _{j=1,2, \ldots, N_{0}}\left|\varphi_{N}(y)-\tilde{\varphi}_{l}^{*}(y)\right|=0$.

Since the surface $D$ is Lyapunov, and the function $\varphi(x) \in W^{2}(M)$, then $\lim _{N \rightarrow \infty} \max _{j=1,2, \ldots, N}\left|\varphi_{N}(y)-\varphi_{j}^{*}(y)\right|=0$.

The Theorem is proved. 
The computational scheme for the external Dirichlet problem is substantiated in a similar way. For internal and external Neumann problems the unique solvability of the splinecollocation method with zero-order splines is proved.

The system of equations (4.10) is solved by the continuous method of solving operator equations. Its implementation is described above when considering $2 \mathrm{D}$ and $3 \mathrm{D}$ problems.

Let us present the results of numerical simulation of the solution of the Helmholtz equation in domains with a smooth boundary.

Let us present the results of solving the internal and external 3D Dirichlet task for the Helmholtz equations with boundary condition $f(x, y, z)=5$ on the sphere $x^{2}+y^{2}+z^{2}=1$. Also we will present the results of solving the internal and external 3D Neumann problems for the Helmholtz equations with boundary condition $\partial f(x, y, z) / \partial \bar{v}=5$ on the sphere $x^{2}+y^{2}+z^{2}=1$. Here $\bar{v}$ is unit normal vector to the sphere $x^{2}+y^{2}+z^{2}=1$. The problem was solved in a spherical coordinate system. The grid of nodes $\left(R, \theta_{k}, \varphi_{l}\right), k=0,1, \ldots, n_{1}, l=$ $0,1, \ldots, n_{2}$, was introduced. Through the nodes $\left(R, \theta_{k}, \varphi_{l}\right), k=0,1, \ldots, n_{1}, l=0,1, \ldots, n_{2}$, parallels and meridians were drawn. As a result, the sphere is covered by $N=n_{1} n_{2}$ regions $\Delta_{k, l}, k, l=0,1, \ldots, n$. The centers of the regions $\Delta_{k, l}, k=0,1, \ldots, n_{1}, l=0,1, \ldots, n_{2}$, are taken as collocation nodes.

The results of calculations for the Dirichlet problem are given in Table 4.1.

Table 4.1. Internal and External 3D Tasks for Dirichlet Problem

Таблица 4.1. 3D внутренние и внешние задачи Дирихле

\begin{tabular}{|c|c|c|c|c|c|}
\hline Dirichlet problem & \multirow{2}{*}{$\mathrm{N}$} & \multicolumn{2}{|c|}{ Internal task } & \multicolumn{2}{c|}{ External task } \\
\cline { 3 - 6 } $\mathrm{k}$ & $\varepsilon_{1}$ & $\varepsilon_{2}$ & $\varepsilon_{1}$ & $\varepsilon_{2}$ \\
\hline 0.5 & 80 & 0.0165725 & 0.00796006 & 0.00155752 & 0.00962531 \\
0.5 & 240 & 0.00806834 & 0.00366256 & 0.000599909 & 0.00360849 \\
1 & 80 & 0.0186016 & 0.00824733 & 0.00191118 & 0.00343365 \\
1 & 240 & 0.00946607 & 0.00376398 & 0.000733595 & 0.00116734 \\
5 & 80 & 0.210381 & 0.0423799 & 0.0089195 & 0.0037427 \\
5 & 240 & 0.0482807 & 0.0120712 & 0.00375413 & 0.00158744 \\
10 & 80 & 0.720814 & 0.173546 & 0.0254282 & 0.00325667 \\
10 & 240 & 0.473627 & 0.089815 & 0.0148006 & 0.000953392 \\
50 & 80 & - & - & 0.318658 & 0.00518162 \\
50 & 240 & - & - & 0.158777 & 0.00692083 \\
\hline
\end{tabular}

The results of calculations for the Neumann problem are given in Table 4.2.

By $\varepsilon_{1}$ we denote the error obtained when solving the Dirichlet problem for the Helmholtz equation by the method of hypersingular integral equations of the first kind, $\varepsilon_{2}$ denotes the error obtained when reducing the Dirichlet and Neumann problems for the Helmholtz equation to the Fredholm equation of the second kind. The modulus of the wave number is denoted by $k$. 
Table 4.2. Internal and External 3D Tasks for Neumann Problem

Таблица 4.2. 3D внутренние и внешние задачи Неймана

\begin{tabular}{|c|c|c|c|}
\hline $\begin{array}{c}\text { Neumann problem } \\
\mathrm{k}\end{array}$ & $\mathrm{N}$ & $\begin{array}{c}\text { Internal task } \\
\varepsilon_{2}\end{array}$ & $\begin{array}{c}\text { External task } \\
\varepsilon_{2}\end{array}$ \\
\hline 0.5 & 80 & 1.03246 & 0.000587054 \\
0.5 & 240 & 0.395273 & 0.000223925 \\
1 & 80 & 0.0875912 & 0.000558534 \\
1 & 240 & 0.0310176 & 0.000188801 \\
5 & 80 & 0.0155207 & 0.000359148 \\
5 & 240 & 0.00659237 & 0.000160749 \\
10 & 80 & 0.0185102 & 0.000674467 \\
10 & 240 & 0.0092024 & 0.000289515 \\
50 & 80 & 0.0276603 & 0.000625453 \\
50 & 240 & 0.00851501 & 0.00163204 \\
\hline
\end{tabular}

Let us present the results of solving the Helmholtz equation in domains with piecewise smooth surfaces. Regularization was carried out by the Wiener method.

Internal and external Dirichlet problems on a plane was reduced to hypersingular integral equations of the first kind and, using the method of double layer potentials, to the Fredholm equation of the second kind. The calculation results are presented in the Table 4.3.

Table 4.3. The Internal Dirichlet Problem on the Square $\Omega$

Таблица 4.3. Внутренняя задача Дирихле в квадрате $\Omega$.

\begin{tabular}{|c|c|c|c|c|c|}
\hline $\begin{array}{c}\text { Dirichlet } \\
\text { problem } \\
\mathrm{d}\end{array}$ & $\begin{array}{c}\text { Internal } \\
\text { task } \\
\mathrm{n}\end{array}$ & $\varepsilon_{1}$ & $\varepsilon_{2}$ & $\varepsilon_{1}$ & $\varepsilon_{2}$ \\
\hline 0.1 & 10 & 0.00213411 & 0.000224903 & 0.0128316 & 0.0126578 \\
0.1 & 20 & 0.00184517 & 0.000105285 & 0.0122158 & 0.0120572 \\
0.1 & 50 & 0.00391174 & $8.24397 \mathrm{e}-05$ & 0.0108303 & 0.0106801 \\
0.01 & 10 & 0.0110965 & 0.0110993 & 0.0107978 & 0.010798 \\
0.01 & 20 & 0.0110512 & 0.011053 & 0.00891222 & 0.00891234 \\
0.01 & 50 & 0.00391174 & 0.00391142 & 0.00449703 & 0.00449608 \\
0.001 & 10 & 0.00612334 & 0.00612343 & 0.00751996 & 0.00751996 \\
0.001 & 20 & 0.00633153 & 0.00633159 & 0.00554193 & 0.00554193 \\
0.001 & 50 & 0.00139693 & 0.00139699 & 0.00281375 & 0.00281374 \\
0.0001 & 10 & 0.0055992 & 0.0055992 & 0.00717709 & 0.00717709 \\
0.0001 & 20 & 0.00585335 & 0.00585335 & 0.00585333 & 0.00585333 \\
0.0001 & 50 & $1.48831 \mathrm{e}-05$ & $1.48831 \mathrm{e}-05$ & 0.000112018 & 0.000112018 \\
\hline
\end{tabular}

Note: Here $\Omega=[-1,1]^{2}$, $\mathrm{d}$ is the rounding radius at the corners of the square, $\mathrm{n}$ is the number of segments into which each side of the square is divided, and $\varepsilon_{1}, \varepsilon_{2}$ are errors in the metric of space $C(\Omega)$. Here $\varepsilon_{1}$ is error when the boundary condition is approached as the value is displaced from the nearest boundary, $\varepsilon_{2}$ is the error when the boundary condition is approached as the average value over 5 points of the border. Exact solution is $\left.u^{*}(x, y)=(x+1) \cos k x+2 \sin k x\right), k=1$.

Примечание: Здесь $\Omega=[-1,1]^{2}, \mathrm{~d}$ - радиус округления углов квадрата, $\mathrm{n}$ - количество сегментов, на которые делится каждая сторона квадрата, а $\varepsilon_{1}, \varepsilon_{2}$ - погрешности решения уравнения в метрике пространства $C(\Omega)$. Здесь $\varepsilon_{1}$ - погрешность решения при аппроксимации граничного условия в точке на гладкой границе значением в ближайшей точке исходной границы, $\varepsilon_{2}$ - 
погрешность при аппроксимации граничного условия в точке на гладкой границе средним значением по 5 точкам исходной границы. Точное решение: $u^{*}(x, y)=(x+1) \cos k x+2 \sin k x, k=1$.

The internal Neumann problem on the plane solved by the method of double layer potentials. The calculating scheme was constructed for the Fredholm equation of the second kind. The calculation results are presented in the Table 4.4 .

Table 4.4. Method of hypersingular integral equations of the second kind for internal Neumann problem

Таблица 4.4. Решение внутренней задачи Неймана. Метод гиперсингулярных интегральных уравнений второго рода

\begin{tabular}{|c|c|c|c|}
\hline $\begin{array}{c}\text { Neumann problem } \\
\mathrm{d}\end{array}$ & $\begin{array}{c}\text { Internal task } \\
\mathrm{n}\end{array}$ & $\varepsilon_{1}$ & $\varepsilon_{2}$ \\
\hline 0.1 & 10 & 0.0203548 & 0.00835932 \\
0.1 & 20 & 0.0340605 & 0.0305454 \\
0.1 & 50 & 0.0418156 & 0.0406616 \\
0.01 & 10 & 0.0760089 & 0.0759413 \\
0.01 & 20 & 0.0423401 & 0.0422682 \\
0.01 & 50 & 0.00932829 & 0.00927824 \\
0.001 & 10 & 0.0894408 & 0.0894401 \\
0.001 & 20 & 0.0548243 & 0.0548236 \\
0.001 & 50 & 0.0258951 & 0.0258947 \\
0.0001 & 10 & 0.0929163 & 0.0929163 \\
0.0001 & 20 & 0.0579243 & 0.0579243 \\
0.0001 & 50 & 0.0296693 & 0.0296692 \\
\hline
\end{tabular}

Note: Here $\Omega=[-1,1]^{2}$, $\mathrm{d}$ is the rounding radius at the corners of the square, $\mathrm{n}$ is the number of segments into which each side of the square is divided, and $\varepsilon_{1}, \varepsilon_{2}$ are errors in the metric of space $C(\Omega)$. Here $\varepsilon_{1}$ is error when the boundary condition is approached as the value is displaced from the nearest boundary, $\varepsilon_{2}$ is the error when the boundary condition is approached as the average value over 5 points of the border. Exact solution is $u^{*}(x, y)=(x+1) \cos k x+2 \sin k x, k=1$.

Примечание: Здесь $\Omega=[-1,1]^{2}, \mathrm{~d}$ - радиус округления углов квадрата, $\mathrm{n}$ - количество сегментов, на которые делится каждая сторона квадрата, а $\varepsilon_{1}, \varepsilon_{2}$ - погрешности решения уравнения в метрике пространства $C(\Omega)$. Здесь $\varepsilon_{1}$ - погрешность решения при аппроксимации граничного условия в точке на гладкой границе значением в ближайшей точке исходной границы, $\varepsilon_{2}-$ погрешность при аппроксимации граничного условия в точке на гладкой границе средним значением по 5 точкам исходной границы. Точное решение: $u^{*}(x, y)=(x+1) \cos k x+2 \sin k x, k=1$.

Internal 3D Dirichlet problem was reduced to hypersingular integral equations of the first kind. Also internal 3D Dirichlet problem was solved by the method of double layer potentials. The calculating scheme was constructed for the Fredholm equation of the second kind. Results of calculation are given in the Table 4.5. 
Table 4.5. 3D Internal Dirichlet Problem in Cube $\Omega$

Таблица 4.5. 3D внутренняя задача Дирихле в кубе $\Omega$

\begin{tabular}{|c|c|c|c|}
\hline $\begin{array}{c}\text { Dirichlet problem } \\
\mathrm{d}\end{array}$ & $\begin{array}{c}\text { Internal task } \\
\mathrm{n}\end{array}$ & $\varepsilon_{1}$ & $\varepsilon_{2}$ \\
\hline 0.1 & 5 & 0.00110805 & 0.00529278 \\
0.1 & 8 & 0.000426094 & 0.00204103 \\
0.1 & 10 & 0.00251942 & 0.0034902 \\
0.01 & 5 & 0.0029991 & 0.00581462 \\
0.01 & 8 & 0.00301313 & 0.00608984 \\
0.01 & 10 & 0.000544667 & 0.00152193 \\
0.001 & 5 & 0.0036374 & 0.00586556 \\
0.001 & 8 & 0.00117232 & 0.00238229 \\
0.001 & 10 & 0.000680864 & 0.00153978 \\
0.0001 & 5 & 0.00385141 & 0.00587077 \\
0.0001 & 8 & 0.00124549 & 0.00238498 \\
0.0001 & 10 & 0.000724935 & 0.00154162 \\
\hline
\end{tabular}

Note: Here $\Omega=[-1,1]^{3}, \mathrm{~d}$ is the rounding radius at the corners of the cube, $\mathrm{n}$ is the number of segments into which each side of the cube is divided, and $\varepsilon_{1}, \varepsilon_{2}$ are errors in the metric of space $C(\Omega)$. Here $\varepsilon_{1}$ is error when the boundary condition is approached as the value is displaced from the nearest boundary , $\varepsilon_{2}$ is the error when the boundary condition is approached as the average value over 5 points of the border. Exact solution is $u^{*}\left(x_{1}, x_{2}, x_{3}\right)=\left(\cos 0.7 x_{1}+2 \sin 0.7 x_{1}\right)\left(\cos 0.6 x_{2}+\right.$ $\left.2 \sin 0.6 x_{2}\right)\left(\cos \sqrt{15} x_{3}+2 \sin \sqrt{15} x_{3}\right), k=1$.

Примечание: Здесь $\Omega=[-1,1]^{3}, \mathrm{~d}$ - радиус округления вершин куба, $\mathrm{n}$ - количество сегментов, на которые делится каждая сторона куба, а $\varepsilon_{1}, \varepsilon_{2}$ - точность решения уравнения в метрике пространства $C(\Omega)$. Здесь $\varepsilon_{1}$ - погрешность решения при аппроксимации граничного условия в точке на гладкой границе значением в ближайшей точке исходной границы, $\varepsilon_{2}$ - погрешность при аппроксимации граничного условия в точке на гладкой границе средним значением по 5 точкам исходной границы. Точное решение: $u^{*}\left(x_{1}, x_{2}, x_{3}\right)=\left(\cos 0.7 x_{1}+2 \sin 0.7 x_{1}\right)\left(\cos 0.6 x_{2}+\right.$ $\left.2 \sin 0.6 x_{2}\right)\left(\cos \sqrt{15} x_{3}+2 \sin \sqrt{15} x_{3}\right), k=1$.

Internal 3D Neumann problem solved by the method of double layer potentials. The calculating scheme was constructed for the Fredholm equation of the second kind. The calculation results are presented in the Table 4.6

Table 4.6. Method of Double Layer Potentials for Internal Neumann Problem in the Cube $\Omega$

Таблица 4.6. Метод потенциалов двойного слоя для внутренней задачи Неймана в кубе $\Omega$

\begin{tabular}{|c|c|c|}
\hline $\begin{array}{c}\text { Neumann problem } \\
\mathrm{d}\end{array}$ & $\begin{array}{c}\text { Internal task } \\
\mathrm{n}\end{array}$ & $\varepsilon$ \\
\hline 0.01 & 5 & 0.194361 \\
0.01 & 10 & 0.158837 \\
0.001 & 5 & 0.187427 \\
0.001 & 10 & 0.123524 \\
0.0001 & 5 & 0.184671 \\
0.0001 & 10 & 0.115699 \\
0.00001 & 5 & 0.184395 \\
0.00001 & 10 & 0.119485 \\
\hline
\end{tabular}

И. В. Бойков, В. А. Руднев, А. И. Бойкова, Н. С. Степанов. Применение непрерывного операторного... 
Note: Here $\Omega=[-1,1]^{3}$, $\mathrm{d}$ is the rounding radius at the corners of the cube, $\mathrm{n}$ is the number of segments into which each side of the cube is divided, and $\varepsilon$ is error in the metric of space $C(\Omega)$. Exact solution is $u^{*}\left(x_{1}, x_{2}, x_{3}\right)=\left(\cos 0.7 x_{1}+2 \sin 0.7 x_{1}\right)\left(\cos 0.6 x_{2}+2 \sin 0.6 x_{2}\right)\left(\cos \sqrt{15} x_{3}+\right.$ $\left.2 \sin \sqrt{15} x_{3}\right), k=1$.

Примечание: Здесь $\Omega=[-1,1]^{3}$, d - радиус округления вершин куба, $\mathrm{n}$ - количество сегментов, на которые делится каждая сторона куба, а $\varepsilon_{1}, \varepsilon_{2}$ - ошибки в метрике пространства $C(\Omega)$. Здесь $\varepsilon_{1}$ - погрешность решения при аппроксимации граничного условия в точке на гладкой границе значением в ближайшей точке исходной границы, $\varepsilon_{2}$ - погрешность при аппроксимации граничного условия в точке на гладкой границе средним значением по 5 точкам исходной границы. Точное решение: $u^{*}\left(x_{1}, x_{2}, x_{3}\right)=\left(\cos 0.7 x_{1}+2 \sin 0.7 x_{1}\right)\left(\cos 0.6 x_{2}+2 \sin 0.6 x_{2}\right)\left(\cos \sqrt{15} x_{3}+\right.$ $\left.2 \sin \sqrt{15} x_{3}\right), k=1$.

The above theorems on the application of the Fredholm integral equations of the first and second kind to the solution of the Helmholtz equation with the Dirichlet and Neumann boundary conditions are valid when the equations are defined in domains with smooth surfaces or, after Wiener regularization, to equations defined in domains with piecewise smooth surfaces.

Therefore, it is of interest to study the applicability of the operator method in the case of piecewise smooth surfaces without any regularization.

It is the most instructive to compare the Dirichlet and the Neumann problems with respect to solving them with the continuous operator method. For this purpose we discuss the example of a plane wave scattering off a regular triangle.

The Dirichlet problem features a weakly singular integral kernel (logarithmic divergence), which warrants resolvability of the problem. The continuous operator method, though, converges slowly and only for a limited range of sufficiently small wave numbers. Minimization of the logarithmic norm by normalizing the phase appropriately (4.5) makes it possible to extend the range of convergence, but only marginally. For example, for $k=1.7$ minimization of the logarithmic norm makes the continuous operator method converge. Indeed, with $\beta \equiv 1 \Lambda_{1}=0.929, \Lambda_{3}=0.929$ and $\Lambda_{2}=0.195$, and no convergence is observed. Choosing $\beta_{l}$ appropriately we get $\Lambda_{1}=0.927, \Lambda_{3}=0.927$ and $\Lambda_{2}=-0.004$, the latter ensures the convergence. For higher wave numbers the method does not converge for the Dirichlet problem even with this log-norm minimization trick.

In contrast, the Neumann problem integral kernel is strongly singular (quadratic singularity), which requires a special treatment of the singular kernel (see [2]). With this stronger singularity of the kernel for the Neumann problem all the logarithmic norms of the operator remain negative for any value of the wave number. The appropriate choice of the phase factor (4.5) becomes even more critical in this case, as it is the diagonal element which determines the logarithmic norm, and neglecting the phase normalization could just ruin the convergence. It is worth noticing, that for denser grids the continuous operator method requires even a smaller number of arithmetic operations than solving the equations directly by gaussian elimination. This is illustrated in Table 4.7, where we show the number of matrix multiplication calls required to achieve a given accuracy for a plane wave scattered off a regular triangle. For the both types of boundary condition we employ the 2-nd order Euler method and the 4-th order Runge-Kutta method with identical - though non-optimal - time steps $h=0.125$. We see clearly that a very rapid convergence is observed in the case of strongly singular Neumann problem. 
Table 4.7. Convergence table for $k=1.7$ for a weakly (Dirichlet problem) and a strongly singular (Neumann problem) integral kernels.

Таблица 4.7. Таблица сходимости при $k=1.7$ слабо (граничное условие Дирихле) и сильно сингулярных (граничное условие Неймана) интегральных ядер.

\begin{tabular}{|c|c|c|}
\hline Residue & \multicolumn{2}{|c|}{ Matrix multiplication calls } \\
& \multicolumn{2}{|c|}{ Euler(RK4) } \\
norm & Dirichlet problem & Neumann problem \\
\hline $10^{-1}$ & $3126(4028)$ & $4(44)$ \\
$10^{-2}$ & $4679(6468)$ & $6(56)$ \\
$10^{-4}$ & $9178(36716)$ & $9(76)$ \\
$10^{-6}$ & $\mathrm{~N} / \mathrm{A}$ & $12(\mathrm{~N} / \mathrm{A})$ \\
\hline
\end{tabular}

Note: The problem corresponds to a plane wave scattering off a regular triangle. The matrix rank is $n=150$, the time step for solving the differential equation (4.4) is fixed to $h=0.125$.

Примечание: Задача рассеяния плоской волны на правильном треугольнике. Ранг матрицы $n=150$, шаг по времени решения дифференциального уравнения (4.4) равен $h=0.125$.

The solutions of the Helmholtz equation are shown in Figs. 4.1 and Figs. 4.2. For the both cases the wave vector is chosen as $\mathbf{k}=(-1.7,0)^{T}$, and the triangle is slightly tilted with respect to the incoming wave direction.

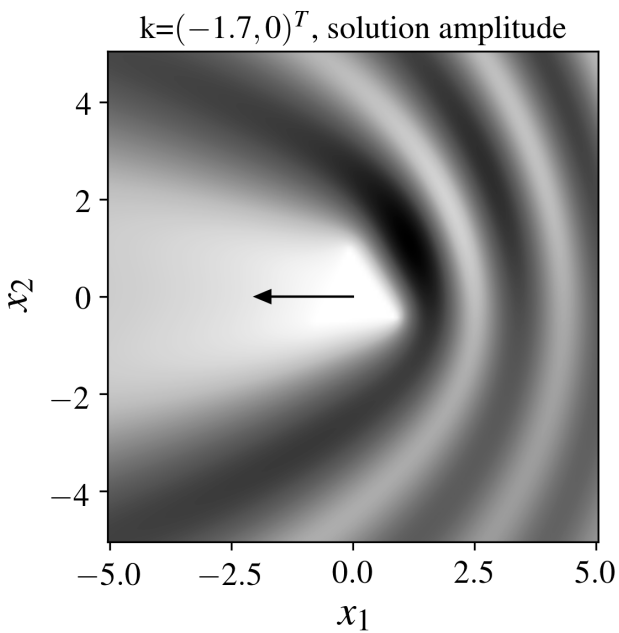

a)

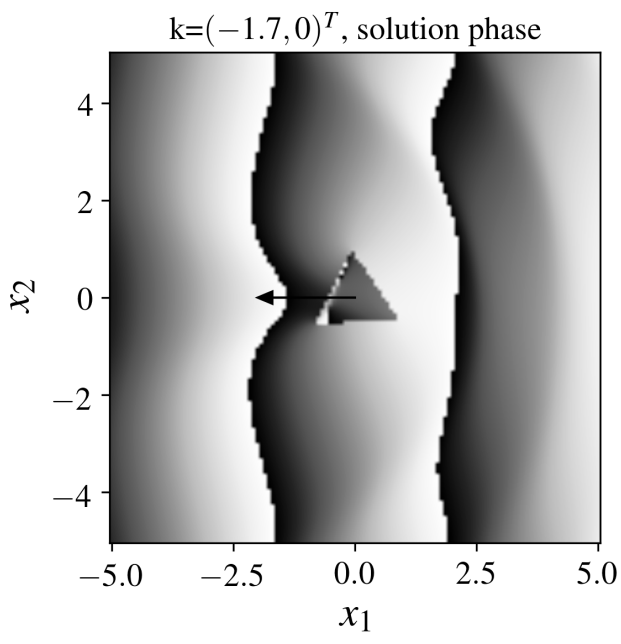

b)

Fig 4.1. The amplitude (a) and the phase (b) of the solution in the vicinity of a scatterer, Dirichlet boundary conditions. The arrow is the wave vector

Рис. 4.1. Амплитуда (a) и фаза (b) решения в окрестности границы (граничное условие Дирихле). Стрелкой обозначен волновой вектор 


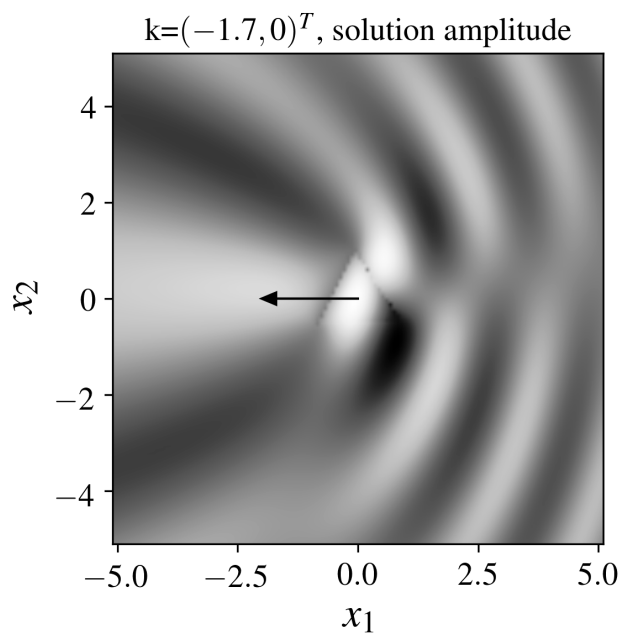

a)

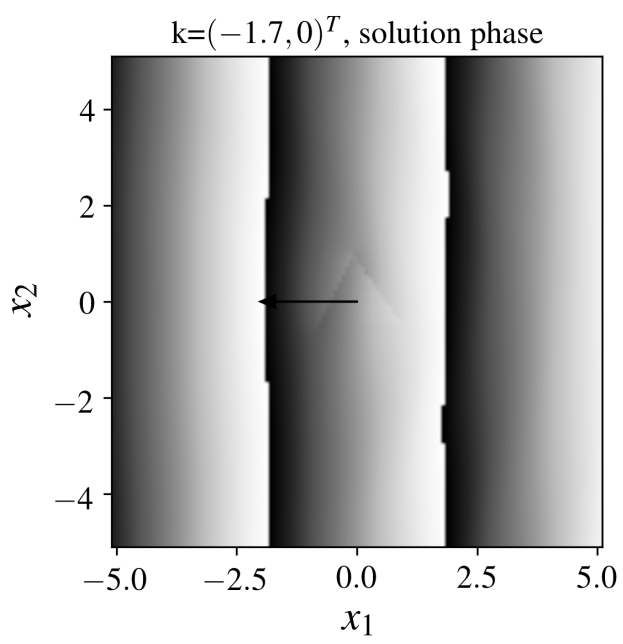

b)

Fig 4.2. The amplitude (a) and the phase (b) of the solution in the vicinity of a scatterer, Neumann boundary conditions. The arrow is the wave vector

Рис. 4.2. Амплитуда (a) и фаза (b) решения в окрестности границы (граничное условие Неймана). Стрелкой обозначен волновой вектор

\section{Inverse tasks}

Consider the Helmholtz equation

$$
\Delta u+k^{2} u=0
$$

where $k=\|k\|>0$ is the wave number corresponding to the wave vector $k$.

The equation (5.1) is defined in the domain $D$ with the boundary $\partial D \in C_{2}$. The solution of the equation (5.1) is a superposition of an incident plane wave and a scattering wave $u=u_{0}(x, k)+\tilde{u}$, where $u_{0}(x, k)$ is a plane wave; $\tilde{u}$ - scattering wave.

Modeling the interaction of an incident wave with a scattering surface leads to equations of the form (5.1) with the Dirichlet and Neumann boundary conditions.

Let's construct a computational scheme for determining the wave number. For definiteness, we restrict ourselves to considering the internal problem in the threedimensional case.

Let the values of $u(x)$ and $\partial u / \partial \nu$ are known on the boundary $\partial D$, where $\nu$ is the unit outward normal vector. To construct a computational scheme, we will use the formula [3]

$$
\frac{1}{4 \pi} \int_{\partial D}\left[u(y) \frac{\partial}{\partial \nu(y)} \frac{e^{i k|x-y|}}{|x-y|}-\frac{\partial u}{\partial \nu}(y) \frac{e^{i k|x-y|}}{|x-y|}\right] d s(y)=\left\{\begin{array}{c}
-u(x), \quad x \in D, \\
0, \quad x \in R^{3} \backslash \bar{D} .
\end{array}\right.
$$

Let at some point $x^{*} \in D$ the solution $u(x)$ of the equation (5.1) is known under known boundary conditions.

Then

$$
\begin{gathered}
\frac{1}{4 \pi} \int_{\partial D}\left[u(y) \frac{\partial}{\partial \nu(y)} \frac{e^{i k\left|x^{*}-y\right|}}{\left|x^{*}-y\right|}-\frac{\partial u}{\partial \nu}(y) \frac{e^{i k\left|x^{*}-y\right|}}{\left|x^{*}-y\right|}\right] d s(y)= \\
=-u\left(x^{*}\right), \quad x^{*} \in D .
\end{gathered}
$$


To find the wave number $k$, we use a continuous method for solving nonlinear operator equations

$$
\begin{gathered}
\frac{d k(t)}{d t}= \\
=\beta\left(\frac{1}{4 \pi} \int_{\partial D}\left[u(y) \frac{\partial}{\partial \nu(y)} \frac{e^{i k(t)\left|x^{*}-y\right|}}{\left|x^{*}-y\right|}-\frac{\partial u}{\partial \nu}(y) \frac{e^{i k(t)\left|x^{*}-y\right|}}{\left|x^{*}-y\right|}\right] d s(y)+u\left(x^{*}\right)\right),
\end{gathered}
$$

where $\beta= \pm 1$ and is chosen so that the logarithmic norm of the derivative of the operator

$$
H(k)=\int_{\partial D}\left[u(y) \frac{\partial}{\partial \nu(y)} \frac{e^{i k(t)\left|x^{*}-y\right|}}{\left|x^{*}-y\right|}-\frac{\partial u}{\partial \nu}(y) \frac{e^{i k(t)\left|x^{*}-y\right|}}{\left|x^{*}-y\right|}\right] \varphi(y) d s(y)
$$

was negative.

To build a computational circuit, the integral

$$
\int_{\partial D}\left[u(y) \frac{\partial}{\partial \nu(y)} \frac{e^{i k(t)\left|x^{*}-y\right|}}{\left|x^{*}-y\right|}-\frac{\partial u}{\partial \nu}(y) \frac{e^{i k(t)\left|x^{*}-y\right|}}{\left|x^{*}-y\right|}\right] \varphi(y) d s(y)
$$

is approximated by a cubature formula.

The differential equation (5.2) is solved by Euler's method. As a result, we arrive at the following iterative process

$$
k_{m+1}=k_{m}+\beta h\left(\frac{1}{4 \pi} \int_{\partial D}\left[u(y) \frac{\partial}{\partial \nu(y)} \frac{e^{i k_{m}\left|x^{*}-y\right|}}{\left|x^{*}-y\right|}-\frac{\partial u}{\partial \nu}(y) \frac{e^{i k_{m}\left|x^{*}-y\right|}}{\left|x^{*}-y\right|}\right] d s(y)+u\left(x^{*}\right)\right)
$$

where $h$ is the step of the Euler method.

But if $\partial D$ is piecewise smooth, then instead of the classical solution we will consider the generalized by Wiener solution of the equation (5.1).

Let $F(x)$ and $G(x)$ be continuous functions in $\bar{D}$ that coincide with $u$ and $\frac{\partial u}{\partial v}$ on $\partial D$, respectively. Let us denote by $u_{i}(x)$ the solution of the equation (5.1) in $D_{i}$ satisfying the condition $\left.u_{i}\right|_{\partial D_{i}}=F$ and $\left.\frac{\partial u_{i}}{\partial v}\right|_{\partial D_{i}}=G$.

Suppose the equation (5.1) is solvable in the domains $D_{i}$. Using the Wiener generalized solution to the equation (5.1) in the domain $D$ we mean the function $u(x)=\lim _{i \rightarrow \infty} u_{i}(x)$, $x \in D$, if such a limit exists and does not depend on the choice of the sequence of domains $D_{i}$ and on the way of constructing the functions $F$ or $G$.

Thus, the computational scheme (5.3) for a piecewise-smooth region will have the following form

$$
k_{m+1}=k_{m}+\beta h\left(\frac{1}{4 \pi} \int_{\partial D_{i}}\left[F(y) \frac{\partial}{\partial \nu(y)} \frac{e^{i k_{m}\left|x^{*}-y\right|}}{\left|x^{*}-y\right|}-G(y) \frac{e^{i k_{m}\left|x^{*}-y\right|}}{\left|x^{*}-y\right|}\right] d s(y)+u_{i}\left(x^{*}\right)\right) .
$$

Let us give a model example illustrating the effectiveness of the method.

Let be $D=[-1,1]^{3}$. Exact solution of the Helmholtz equation (5.1) in $D$ is equal $u(x, y, z)=\left(\cos 0.7 x_{1}+2 \sin 0.7 x_{1}\right)\left(\cos 0.6 x_{2}+2 \sin 0.6 x_{2}\right)(\cos \sqrt{15}+2 \sin \sqrt{15}), k^{2}=l^{2}+$ $+m^{2}+r^{2}, l=0.7, m=0.6, r=\sqrt{15}$.

Instead of the initial boundary of the region $\partial D$, we will consider the following sequence of surfaces $\partial D_{i}=\left\{\bigcup_{j=1}^{6} L_{i j} \cup \bigcup_{j=1}^{12} S_{i j} \cup \bigcup_{j=1}^{8} R_{i j}\right\}$, where $L_{i j}$ are planes with indents from 
the edges at a distance $d_{i}, S_{i j}$ are cylindrical surfaces indented from the ribs by a distance $d_{i}$ with radius $d_{i}$ and a height equal to $2-d_{i}, R_{i j}$ is spherical surfaces indented from the vertices by a distance $d_{i}$ for each variable and with radius $d_{i}$.

The calculation results for the inverse problem of wave detection are shown in the Table 5.1. Here $k^{*}$ is the exact value of the wavenumber, $d_{i}$ is the rounding radius of the vertices and edges of the cube, $M$ is the number of iterations of the Euler method, $\varepsilon$ is the determination error, $\varepsilon_{1}$ is the residual.

Table 5.1. Reconstruction of the wavenumber

Таблица 5.1. Восстановление волнового числа

\begin{tabular}{|l|l|l|l|l|}
\hline$k^{*}$ & $d_{i}$ & $M$ & $\varepsilon$ & $\varepsilon_{1}$ \\
\hline 0.5 & 0.001 & 200 & $5.27961 \mathrm{e}-05$ & $1.55197 \mathrm{e}-07$ \\
\hline 0.5 & 0.0001 & 200 & $5.35118 \mathrm{e}-06$ & $1.55116 \mathrm{e}-07$ \\
\hline 0.5 & 0.00001 & 200 & $6.343 \mathrm{e}-07$ & $1.55108 \mathrm{e}-07$ \\
\hline 1 & 0.001 & 200 & $6.0594 \mathrm{e}-05$ & $1.64743 \mathrm{e}-14$ \\
\hline 1 & 0.0001 & 200 & $6.05479 \mathrm{e}-06$ & $1.68754 \mathrm{e}-14$ \\
\hline 1 & 0.00001 & 200 & $6.05292 \mathrm{e}-07$ & $1.73196 \mathrm{e}-14$ \\
\hline 5 & 0.001 & 200 & $6.00708 \mathrm{e}-05$ & 0.000559045 \\
\hline 5 & 0.0001 & 200 & $5.19241 \mathrm{e}-05$ & 0.000559247 \\
\hline 5 & 0.00001 & 200 & $5.22667 \mathrm{e}-05$ & 0.000559268 \\
\hline
\end{tabular}

\section{Discussion}

The paper demonstrates the application of a continuous method for solving nonlinear operator equations to direct and inverse problems of solving the Helmholtz equation. In the case of linear equations, the method is of theoretical interest, since allows one to justify approximate methods for solving operator equations without invertibility of the initial operator. In the case of nonlinear equations, the method is realizable when the Frechet (Gateau) derivative is uninvertible in the neighborhood of the initial value.

Analysis of the solution of model examples allows us to make the following conclusions:

1) The accuracy of solving the $3 \mathrm{D}$ internal and external Dirichlet problems is of the same order, both when using hypersingular integral equations of the first kind, and when applying weakly singular integral equations of the second kind;

2) The computational scheme for solving hypersingular integral equations constructed in the article diverges when solving the 3D Neumann problem. This is due to the fact that the piecewise constant approximation of the desired solution is insufficient in $3 \mathrm{D}$ hypersingular integral equations;

3) When solving 2D of the Dirichlet problem in a domain with a piecewise smooth boundary, the superiority of the method of hypersingular integral equations of the first kind is obvious;

4) When solving the $3 \mathrm{D}$ Neumann problem in a domain with a piecewise smooth surface, the method of hypersingular integral equations diverges.

It is obvious that there is a need to develop numerical methods for solving 3D hypersingular integral equations by spline-collocation methods with splines of the first and higher orders.

In the fifth section, the continuous operator method is applied to solving the problem of reconstructing the wave number for the Helmholtz equation. The efficiency of the proposed 
computational scheme is demonstrated.

It is of considerable interest to extend the results obtained above to other formulations of inverse scattering problems.

Acknowledgments. The authors thank the Russian Foundation for Basic Research for support within grant 16-01-00594 (I.B. and A.B) and for partial support within grant 18-02-00492 (V.R.).

\section{REFERENCES}

1. I. V. Boikov, "On a Continuous Method for Solving Nonlinear Operator Equations", Differential Equations, 48:9 (2012), 1308-1314.

2. I. V. Boikov, V. A. Roudnev, A. I. Boikova, O. A. Baulina, "New Iterative Method for Solving Linear and Nonlinear Hypersingular Integral Equations", Applied Numerical Mathematics, 127 (2018), 280-305.

3. D. Colton, R. Kress, Integral Equation Methods in Scattering Theory, John Wiley \& Sons, New York, 1983, 287 p.

4. S. G. Daeva, A. V. Setukha, "[On the Numerical Solution of the Neumann Boundary Value Problem for the Helmholtz Equation by the Method of Hypersingular Integral Equations]", Computational Methods and Programming, 16:3 (2015), 421-435 (In Russ.).

5. I. V. Boikov, N. V. Moiko, "Approximate Solution of the Helmholtz Equation", Proceedings of the International Conference on Computation Mathematics, 2002, 374-380 (In Russ.).

6. Z. Y. Yan, K. C. Hung, H. Zheng, "Solving the Hypersingular Boundary Integral Equation in Three-Dimensional Acoustics a Regularization Relationship", J. Acoust. Soc. Am., 113:5 (2003), 2674-2683. DOI: https://doi.org/10.1121/1.1560164

7. I. A. Tsukerman, "Singularity-Free Boundary Equation Method for Wave Scattering", IEEE Trans. Antennas Propag., 59:2 (2011), 555-562. DOI: https://doi.org/10.1109/TAP.2010.2096189

8. Yu. L. Daletskii, M. G. Krein, Stability of Solutions of Differential Equations in Banach Space, Nauka Publ., Moscow, 1970 (In Russ.), 386 p.

9. K. Dekker, J. G. Verwer, Stability of Runge-Kutta Methods for Stiff Nonlinear Differential Equations, North Holland Publishing Co., Amsterdam, 1984, 386 p.

10. S. M. Lozinskii, "Note on a paper by V.S. Godlevskii", USSR Computational Mathematics and Mathematical Physics, 13:2 (1973), 457-459 (In Russ.).

11. V. A. Kondrat'ev, O. A. Oleinik, "Boundary-Value Problems for Partial Differential Equations in Non-Smooth Domains", Uspekhi Mat. Nauk, 38:2 (1983), 3-76 (In Russ.).

12. V. M. Babich, M. A. Lyalinovm, V. E. Grikurov, The Sommerfeld-Malyuzhinets Method in the Theory of Diffraction, St. Petersburg State University Publ., St. Petersburg, 2003 (In Russ.), 104 p. 
13. F. Preparata, M. Sheimos, Computational Geometry: An Introduction, Springer-Verlag New York Inc., New York, 1985, 390 p.

14. A. V. Skvortsov, Delaunay Triangulation and Its Application, Tomsk University Publ., Tomsk, 2002 (In Russ.), 128 p.

Submitted 08.07.2021; Revised 10.08.2021; Accepted 25.08.2021

Information about the authors:

Ilya V. Boykov, Professor, Head of the Department of Higher and Applied Mathematics, Penza State University (40 Krasnaya St., Penza 440026, Russian Federation), Dr.Sci. (Physics and Mathematics), ORCID: https://orcid.org/0000-0002-6980-933X, i.v.boykov@gmail.com

Vladimir A. Roudnev, Associate Professor, Department of Computational Physics, Saint Petersburg State University (7/9 University Embankment, , St. Petersburg 199034, Russian Federation), Dr.Sci. (Physics and Mathematics), ORCID: https://orcid.org/0000-0001-6451-5028, v.rudnev@spbu.ru

Alla I. Boykova, Associate Professor, Department of Higher and Applied Mathematics, Penza State University (40 Krasnaya St., Penza 440026, Russian Federation), Ph.D. (Physics and Mathematics), ORCID: https://orcid.org/0000-0003-0436-0460, allaboikova@mail.ru

Nikita S. Stepanov, Student, Penza State University (40 Krasnaya St., Penza 440026, Russian Federation), ORCID: https://orcid.org/0000-0002-4146-9302, ctnik1998@mail.ru

The authors have read and approved the final manuscript.

Conflict of interest: The authors declare no conflict of interest. 


\title{
Применение непрерывного метода решения
}

\section{нелинейных операторных уравнений к прямым и обратным задачам рассеяния}

\author{
И. В. Бойков ${ }^{1}$, В. А. Руднев ${ }^{2}$, А. И. Бойкова ${ }^{1}$, Н. С. Степанов ${ }^{1}$ \\ 1 Пензенский государственный университет (г. Пенза, Российская Федерация) \\ 2 Санкт-Петербургский государственный университет (г. Санкт-Петербург, \\ Российская Федерация)
}

\begin{abstract}
Аннотация. Дано обобщение непрерывного метода решения нелинейных операторных уравнений в банаховых пространствах и описано его применение для исследования прямых и обратных задач теории рассеяния. Непрерывный метод решения нелинейных операторных уравнений основан на Ляпуновской теории устойчивости решений систем обыкновенных дифференциальных уравнений. Он применим к операторным уравнениям в банаховых пространствах, в том числе, и в случаях, когда производная Фреше (Гато) нелинейного оператора необратима в окрестности начального значения. В работе он применяется к решению задач Дирихле и Нейманна для уравнения Гельмгольца и для определения волнового числа в обратной задаче. Рассмотрены внутренние и внешние задачи Дирихле и Нейманна для уравнения Гельмгольца, определенного в областях с гладкими и кусочно- гладкими границами. В случае, когда уравнение Гельмгольца рассматривается в области с гладкой границей, существование и единственность решения следует из классической теории потенциала. При решении уравнения Гельмгольца в областях с кусочно гладкими границами проводится винеровская регуляризация. Задачи Дирихле и Нейманна для уравнения Гельмгольца методами теории потенциала трансформируются в сингулярные интегральные уравнения второго рода и в гиперсингулярные интегральные уравнения первого рода. Для приближенного решения сингулярных и гиперсингулярных интегральных уравнения построены и обоснованы вычислительные схемы методов коллокации и механических квадратур. Особенности непрерывного метода иллюстрируются решением краевых задач для уравнения Гельмгольца. Рассмотрены приближенные методы восстановления волнового числа в уравнении Гельмгольца.
\end{abstract}

Ключевые слова: уравнение Гельмгольца, граничные условия Дирихле и Неймана, обратные задачи, непрерывный метод решения операторных уравнений

Для цитирования: Бойков И. В., Руднев В.А., Бойкова А.И., Степанов Н. С. Применение непрерывного метода решения нелинейных операторных уравнений к прямым и обратным задачам рассеяния // Журнал Средневолжского математического общества. 2021. Т. 23 , № 3. C. 247-272. DOI: https://doi.org/10.15507/2079-6900.23.202103.247-272

\section{СПИСОК ЛИТЕРАТУРЫ}

1. Бойков И. В. Об одном непрерывном методе решения нелинейных операторных уравнений // Дифференциальные уравнения. 2012. Т. 48, № 9. С. 1308-1314.

2. Boikov I. V., Roudnev V. A., Boikova A. I., Baulina O. A. New iterative method for solving linear and nonlinear hypersingular integral equations // Applied Numerical Mathematics. 2018. Vol. 127. pp. 280-305.

3. Colton D., Kress R. Integral equation methods in scattering theory. New York: John Wiley \& Sons, 1983. 287 p. DOI: https://doi.org/10.1002/zamm.19850650104 
4. Даева С. Г., Сетуха А. В. О численном решении краевой задачи Неймана для уравнения Гельмгольца методом гиперсингулярных интегральных уравнений // Вычислительные методы и программирование. 2015. Т. 16, вып. 3. С. 421-435.

5. Boikov I. V., Moiko N. V. Approximate solution of the Helmholtz equation // Proceedings of the International Conference on Computation Mathematics. 2002. pp. $374-380$.

6. Yan Z. Y., Hung K. C., Zheng H. Solving the hypersingular boundary integral equation in three-dimensional acoustics a regularization relationship // J. Acoust. Soc. Am. 2003. Vol. 113, No. 5. pp. 2674-2683. DOI: https://doi.org/10.1121/1.1560164

7. Tsukerman I. A. Singularity-free boundary equation method for wave scattering // IEEE Trans. Antennas Propag. 2011. Vol. 59, No. 2. pp. 555-562. DOI: https://doi.org/10.1109/TAP.2010.2096189

8. Далецкий Ю. Л., Крейн М. Г. Устойчивость решений дифференциальных уравнений в банаховом пространстве. М.: Наука, 1970. 386 с.

9. Деккер К., Вервер Я. Устойчивость методов Рунге-Кутты для жестких нелинейных дифференциальных уравнений. М.: Мир, 1988. 334 с.

10. Лозинский С. М. Замечание о статье В. С. Годлевского // Журнал вычисл. матем. и матем. физ. 1973. Т. 13, № 2. С. 457-459.

11. Кондратьев В. А., Олейник О. А. Краевые задачи для уравнений с частными производными в негладких областях // Успехи математических наук. 1983. Т. 38, вып. 2. С. 3-76.

12. Бабич В. М., Лялинов М. А., Грикуров В. Э. Метод Зоммерфельда-Малюжинца в теории дифракции. СПб.: СПбГУ, 2003. 104 с.

13. Preparata F., Sheimos M. Computational geometry: An introduction. New York: Springer-Verlag New York Inc, 1985. 390 p.

14. Скворцов А. В. Триангуляция Делоне и ее применение. Томск: Изд-во Томск. ун-та, 2002. 128 с.

Поступила 08.07.2021; доработана после рецензирования 10.08.2021; принята к публикации 25.08.2021

Информаиия об авторах:

Бойков Илья Владимирович, профессор, заведующий кафедрой «Высшая и прикладная математика», Пензенский государственный университет (440026, Россия, г. Пенза, ул. Красная, д. 40), доктор физико-математических наук, https://orcid.org/0000-0002-6980933X, i.v.boykov@gmail.com

Руднев Владимир Александрович, доцент, кафедра «Вычислительная физика», Санкт-Петербургский государственный университет (199034, Россия, г. Санкт-Петербург, Университетская наб., 7/9), доктор физико-математических наук, https://orcid.org/0000-00016451-5028,v.rudnev@spbu.ru

Бойкова Алла Ильинична, доцент, кафедра «Высшая и прикладная математика», Пензенский государственный университет (440026, Россия, г. Пенза, ул. Красная, 
д. 40), кандидат физико-математических наук, ORCID: https://orcid.org/0000-0003-0436-0460, allaboikova@mail.ru

Степанов Никита Сергеевич, студент, кафедра «Высшая и прикладная математика», Пензенский государственный университет (440026, Россия, г. Пенза, ул. Красная, д. 40), ORCID: https://orcid.org/0000-0002-4146-9302, ctnik1998@mail.ru

Авторы прочитали и одобрили окончательный вариант рукописи.

Конфликт интересов: авторы заявляют об отсутствии конфликта интересов. 